\title{
AUTOMATED ALGORITHM FOR EXTRACTION OF WETLANDS FROM IRS RESOURCESAT LISS III DATA
}

\author{
S.Subramaniam and Manoj Saxena
}

RS\&GIS Applications Area, National Remote Sensing Centre(NRSC), ISRO, Hyderabad, AP, 500 625, INDIA

KEY WORDS: Wetland, Remote Sensing, automated, knowledge based feature extraction

\begin{abstract}
Wetlands play significant role in maintaining the ecological balance of both biotic and abiotic life in coastal and inland environments. Hence, understanding of their occurrence, spatial extent of change in wetland environment is very important and can be monitored using satellite remote sensing technique. The extraction of wetland features using remote sensing has so far been carried out using visual/ hybrid digital analysis techniques, which is time consuming. To monitor the wetland and their features at National/ State level, there is a need for the development of automated technique for the extraction of wetland features. A knowledge based algorithm has been developed using hierarchical decision tree approach for automated extraction of wetland features such as surface water spread, wet area, turbidity and wet vegetation including aquatic for pre and post monsoon period. The results obtained for Chhattisgarh, India using the automated technique has been found to be satisfactory, when compared with hybrid digital/visual analysis technique.
\end{abstract}

\section{INTRODUCTION}

Among all the ecosystems found on earth's surface, wetland ecosystems play a significant role. It provides most of the fossil fuel that have been preserved in the swampy environment of past geological era. In addition, they are also valuable sources, sinks, and transformers of chemical/biological and a genetic information base with the richest bio-multiplicity. They can be described as the "kidneys of landscape" for the function they perform in hydrologic and chemical cycle and as the downstream receivers of waste from both natural and human sources. They have been found to clean polluted waters, prevent floods, protect shoreline. It does, not only provide foods, resources and water source for human beings, but also recharges ground water source for mitigating drought and natural disaster avoidance. Apart from above, they play major role in the landscape by providing habitat for a wide variety of flora and fauna.

Wetlands have been defined differently by different people/agencies (Ramsar 2004, Cowardin, etal.,1979) for different purposes depending on the objective and the need. They are defined as biophysical flat lands or slopes with perennial water tables at or near the surface. To say in simpler form "wetlands are lands with soils that are periodically flooded". In the present context it is defined as "All submerged or water saturated lands, natural or manmade. inland or coastal, permanent or temporary, static or dynamic, vegetated or non-vegetated, which necessarily have, a land-water interface are defined as wetlands" and this follows the definition of Ramsar Convention.

Wetland is the formation of water-land co-operation with multifunctional ecosystem and highly sensitive to global environmental changes. Particularly in the light of global warming, it is very much necessary to monitor the changes in wetland with regular periodicity. Remote sensing and geographical information system (GIS) integrated with biology and ecology will gain the advantages, which cannot be found in traditional methodologies. It is one of the most effective ways to monitor the dynamic changes of wetland resources. The Multi-spectral remote sensing data has been used for the extraction of wetland information (Md.A. Islam et.al., 2008, Zhang Shu-qing et.al., 2000,
Els R. De Roeck et.al., 2008, Martha S etal., 2008). The Visual and hybrid digital-visual interpretation techniques are most commonly used for the extraction of wetland features. These methods are time consuming and also needs expert analyst leading to subjective evaluation. Hence these methods are not suitable for continuous, periodical monitoring of the wetland for large countries like India, particularly when the effect of climate change on the wetland has to be monitored. Hence there is a need for developing objective estimation of the wetland areas preferably using automated methods.

A semi automatic method for the estimation of the wetlands using Landsat TM+ and SRTM has been developed and used (Md.A. Islam et.al., 2008). An automated method for the mapping of water bodies has been developed using hierarchical, decision tree method at NRSC (Subramaniam.S., et.al., 2010). This paper reports the methodology used for the development of the automated mapping of wetland features and their results obtained in the case of Chhattisgarh state India.

\section{STUDY AREA}

Chhattisgarh state is situated between $80^{\circ} 15^{\prime \prime}$ to $84^{\circ} 20^{\prime \prime} \mathrm{E}$ longitude and between $17^{\circ} 46^{\prime \prime} \mathrm{N}$ to $24^{\circ} 5^{\prime \prime}$.N latitude. Physiographically, the state of Chhattisgarh can be divided into 3 distinct zones Viz., Baster Plateau, Chhattisgarh Plain and Northern Hill region. Bastar plateau region covers the districts of Bastar, Dantawara and Kankar is mostly covered with forests. The hills forming the plateaus achieve heights between 700 and $800 \mathrm{~m}$. The Chhattisgarh Plain represents mature pediplain and is characterised by a gently undulating and flat terrain. The fringe area is distinguished by high mounds or hillocks rising to altitude of $700 \mathrm{~m}$ above msl. The average relief is of about $400 \mathrm{~m}$. The Northern Hill region covers part of Sarguja, Koriya, Korba, Bilaspur, Jaspur and Raigarh districts. It is a part of Maikhal and Hazaribagh ranges of central India.

The climate of Chhattisgarh is mainly tropical. It is hot and humid because of its proximity to the Tropic of Cancer. It is dependent completely on the monsoons for rains. Summer season correspond to April to June and monsoon season is from late June to October. Average rainfall in the state is around 
$1400 \mathrm{~mm}$. and about $90 \%$ of the total rainfall is confined in the Monsoon season i.e. 15th June to September. The rainfall has erratic temporal and spatial distribution in the state. Winter season is from November to January. The Godavari River and its tributaries is important river in the south. The central portion of the state is located in the upper basin of the Mahanadi River and its tributaries. The area is underlain by diverse rock types of different geological ages from Azoic to Quaternary. The Archaean crystallines comprising granites, gneisses form the major litho units of the area. They form discontinuous, unconfined and semi-confined aquifers.

\section{DATABASE}

Resourcesat1 Linear Imaging Self Scanning Sensor (LISS-III) multi-spectral, temporal data for the year 2006-2007 has been used to derive information on wetlands(Figure-3). These datasets were geo-referenced with defined parameters of TM Projection and WGS 84 datum. The geo-referenced images of Post Monsoon (October 2006 ) and pre-Monsoon( April/May 2007) period that represent the maximum and minimum water spread area were used for the analysis and classification of wetlands. Survey of India (SOI) topographical maps on 1:50,000 scale were used during ground data collection.

\section{AUTOMATED EXTRACTION OF WETLAND FEATURES}

The automated extraction of feature categories/classes using remotely sensed data can be implemented using either GIS based supervised classification techniques or knowledge based hierarchical decision tree method. In the GIS method is suitable only for updating the existing class data base. It assumes that the changes in class happens only near the boundary between the feature classes and they covers smaller areal extent. The knowledge based method utilizes all the available invariant or semi-invariant characteristics of the feature categories in a hierarchical, multi-logical decision approach(Baraldi et.al., 2006; Subramaniam etal., 2011). The knowledge based method has been used for the automatic delineation of wetland feature categories such as surface water spread, wetland area, turbidity and wetland vegetation in this study. The knowledge based method has been implemented in multi-logic decision equation using spectral, spatial and contextual based parameters with suitable threshold levels. The selected parameter either support and reinforce the identification of the particular feature class or eliminate the noise feature classes. It is possible to identify and extract the pixels corresponding to the various feature categories with sufficient number of logical decisions. Separate set of logical equations are used for each subcategory of the feature classes, to account for the natural variations in the feature classes and also for the variations due to the geoclimatic impact on the spectral response pattern of the feature class. The threshold values used in these logics are flexible, as these are used for either to reinforce the decision taken with multiple logics and is similar to the approach used by human interpreter in analyzing the image data in visual interpretation technique. The logical equations in general contain one or two essential conditions to identify the presence of a particular class and the other conditions are used for the removal of the noisy feature classes that may have similar response in certain geoclimatic conditions. The feature parameter used in the development of the algorithm are the normalized spectral indices such as NDWI, MNDWI, NDPI, NDTI, NDVI) and spectral band ratios. These spectral indices are defined as given below.

Normalized Difference Water Index(NDWI) has been defined( McFeeters, S.K., 1996)as

NDWI $=($ Green- NIR $) /($ Green + NIR $)$

The Modified Normalized Difference Water Index(MNDWI) defined by Xu, Hanqiu.(2006) as

NDWI $=($ Green- SWIR $) /($ Green + SWIR $)$

to reduce the urban noise in the delineation of water bodies.

Lacaux. J.P., et.al (1986) defined the Normalized Difference Pond Index(NDPI) and Normalized Difference Turbidity Index(NDTI) as

$\mathrm{NDPI}=($ Green-SWIR $) /($ Green + SWIR $)$

$\mathrm{NDTI}=($ Red - Green $) /($ Red + Green $)$

The Normalized Difference Vegetation Index (NDVI) has been defined (Townshend, Justice 1986, C. J. Tuckera and P. J. Sellersa, 1986) as $\mathrm{NDVI}=(\mathrm{NIR}-\mathrm{Red}) /(\mathrm{NIR}+\mathrm{Red})$

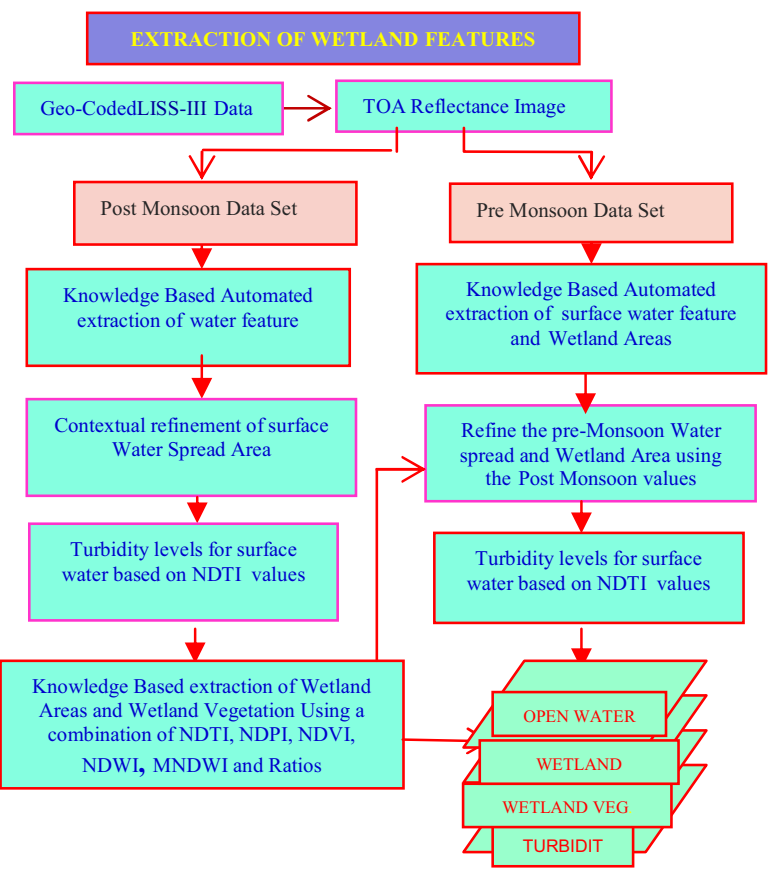

Fig. 1 Schematic of the knowledge based approach for Automated Wet land Feature Extraction

The schematic diagram of knowledge based approach for the automated extraction of the wetland features is shown in figure.1. The detailed methodology used for each of the wetland feature classes has been reported in the following sections.

\subsection{Surface Water Spread}

The extraction of the surface water spread from remotely sensed data has been carried out using visual (Frazier, P. S., and Page, K. J., 2000; Ryu, J. H., et al., 2002) and hybrid digitalvisual(Suresh Babu, A.V., et al., 2003, Manavalan et al., 1983)and supervised classification techniques. Spectral indices based automated extraction of water bodies has been attempted( McFeeters, S.K., 1996; Xu, Hanqiu.(2006) ) and these methods has limitation due to the inclusion of a number of urban, cloud and cloud shadow pixels as water pixels. Subramaniam et 
al.,(2011) has proposed a knowledge based hierarchical decision tree algorithm for the automated extraction of water bodies and has been used for the extraction of water pixels. Further refinements were carried out for the inclusion of the mixed pixels at the edges of the water body. In the case of post monsoon period (having maximum water spread), contiguous pixels to the water body and having positive values for either NDWI or MNDWI and having values with in predefined threshold value for the other feature parameter such as turbidity, NDPI and band ratios is added to the water pixel. Also, pixels having the spectral shape of shallow water pixel and represented in terms of spectral band ratios with small values of negative values of the NDWI and MNDWI has been added to the surface water pixels. This has improved the results considerably for the small water bodies and very shallow water bodies, it includes all the edge pixels that can be visually identified from the image. The threshold values for the various feature parameters vary for different soil background and hence were implemented as different set of conditions. However method is found to be insufficient or inadequate in case of pre-monsoon data sets for water bodies having very shallow water levels, since it has negative NDWI and MNDWI values due to the higher bottom reflectance during the summer period, leading to numbers of these pixels were not identified as water pixel. Hence a modified approach was implemented for the extraction of shallow water pixels. This is based on the fact that in general, the surface water spread will be less for the pre-monsoon(summer) period compared to that in the post monsoon period. In this step, lower levels of threshold for the NDWI, MNDWI, MDPI and band ratios for a given turbidity range values were used to identify water pixels that lies within the area covered by surface water during post monsoon season period. The threshold values vary with varying turbidity index value and spectral band ratios for covering various types of soil background. Accordingly about six sets of multi parameter condition were used in the case of post monsoon data sets in addition to the ten conditional sets were used for the pre monsoon data sets. Figure 2 shows Resourcesat LISS III Data of October 06 and may 07 shows variation in water spread in Tandula reservoir.

The classified image of May shows the surface water spread Post (Blue color) and Pre monsoon in yellow periods as overlay, indicating the seasonal change in water spread. Visual inspection of the results show satisfactory results for both seasonal images.

\subsection{Turbidity}

The Turbidity levels were estimated based on the Normalized Difference Turbidity Index (NDTI) using the spectral reflectance values. As turbidity level of water increases due the increase in the suspended particles in the water, the reflectance of the red band more than that of the green band (Monirul Islam et.al., 2006). This spectral characteristic of the turbid water can be used for the detection of turbid water pixels and has been captured in the Normalized Difference Turbidity Index defined by Lacaux. J.P., et.al .(1986). Based on the analysis of sensor data covering the Indian sub-continent, the variation in the turbidity levels of different water bodies has been found that the NDTI varies from -0.2 to 0.0 in the case of clear water and from 0.0 to 0.2 for the moderately turbid water bodies. In the case of highly turbid water bodies, the NDTI values are found to be greater than +0.25 . The problem associated with the turbidity index for the classification of the water turbidity is that clear shallow water pixels also show NDTI values greater than Zero. This is due to the fact that the increase in the red reflectance is more with respect to the green due to the reflectance of the suspended soils in the turbid water bodies. In the case of the shallow and clear water body, the reflected radiance consists of bottom soil reflectance In addition to the reflectance of the water column. The bottom reflectance is similar to that of suspended soil. Hence the reflectance of the shallow water body has similar to that of the turbid water body and provides NDTI greater than zero and will be classified as moderately turbid water, if it is based only on the NDTI values. To remove these noise pixels, a refinement of the NDTI values has been carried out. It is based on the following observations. 1. The water turbidity occurs essentially in the post monsoon data, as the soil and slit carried by the flowing water causes turbidity in the water bodies and 2. The shallow water bottom reflectance is mostly confined to edge pixels with 2 or 3 pixels in the case of clear water bodies. The implementation of the noise removal is carried out such that if a water pixel is near the edge and the turbidity index value of the 4th pixel inside the water body is less than zero then the NDTI value for the pixel is set to zero. Figure 3 shows the water body having moderate and low levels of turbidity and has been verified during the ground truth investigations.

\subsection{Wetland area}

The wetland area has been defined to include the surface water spread area and the neighboring wetland areas with saturated water in soil. It has been observed from the visual display of the FCC image of Normalized Difference Spectral indices consisting of MNDWI(Blue)-NDPI(Green)-NDTI(Red) that the wet land area with saturated soil lies within 4 pixels (approximately 100 meters) from the surface water pixels. Based on this observation, a knowledge based approach for detection of the wet soil area for the pixels that lies with 4 pixels from the edge of the surface water pixel has been implemented.

The required lower and upper threshold values for the various spectral feature parameters has been selected based on the statistical analysis of the sample pixels extracted from the visually identified wet soil pixels for various soil types and for various water levels of the water body near the edge pixel. The shallowness of the water pixel has the effect as in the case of the mixed edge pixels on the water-soil boundary.

The spectral band reflectance values for large number representative pixel, numbering few hundreds, were extracted from the images of the pre-monsoon and post- monsoon season covering various soil types and geological areas was extracted and analyzed using the various spectral feature parameters. The spectral parameters used for the extraction of wet soil pixels are NDWI, MNDWI, NDPI, NDTI and spectral band ratios. The methodology used in the analysis for the determination of the threshold is similar to those used by Subramaniam et.al for the water pixel extraction for surface water spread area. A multiparameter logical equation are used one each for each type of the soil and for various levels of wetness in the soil in a hierarchical manner and applied to the pixels near the edge of the surface water pixels. A sub-scene of LISS -III FCC image, Spectral indices FCC image and the extracted wetland area (Surface water and near by wet land) are shown in figure 4 . It can be observed that the algorithm is effective for both the clear and highly turbid water cases. 


\subsection{Wetland Vegetation}

It has been reported in literature (Lacaux. J.P., et.al 1986) that Normalized Difference Pond Index (NDPI), when used in conjunction with NDVI, provides better discrimination of the aquatic and wetland vegetation from the normal vegetation compared to the NDVI, which detects all types of vegetation. To understand the utility/importance of the NDPI and NDVI, a simulation study has been carried out using linear mixing principle. For this study, reflectance values of saturated vegetation pixel, deep water pixel and dry soil pixels were extracted for few pixels and averaged to get the representative reflectance values. Table 1 shows the TOA reflectance values of the sample pixels used in the study. The reflectance values of the mixture have been computed in the case of vegetation in water and vegetation in dry soil. The fractional contribution of the mixture varied from zero percent to 100 percent values in steps of 10 percent. The sensitivity analysis results are shown in figure. It can be observed from the plots that 1.The NDPI values increases linearly from +0.35 to +0.45 , in the case of soil-vegetation mixture, while it reduces non-linearly from +0.35 to nearly -0.4 for both clear and turbid water-vegetation mixture. 2.The NDVI values decreases linearly from +0.7 to nearly 0.15 for soil-vegetation mixture and it decreases nonlinearly from +0.7 to -0.06 for clear water-vegetation mixture. In the case of turbid water-vegetation mixture, it goes down to 0.2 .The sensitivity analysis show that with suitable upper bound threshold values, the land based vegetation can be eliminated leaving only the vegetation in wetland areas and in water. This is due to the fact that NDPI, essentially negative of MNDWI, has used for the identification of the wetland areas and water because of the high absorption of the SWIR radiation water.

$\begin{array}{lllll} & \text { Green } & \text { Red } & \text { NIR } & \text { SWIR } \\ \text { Water(\%) } & 0.093018 & 0.065918 & 0.058105 & 0.036377 \\ \text { Water(Tubid) } & 0.093506 & 0.102539 & 0.057617 & 0.036865 \\ \text { Vegetation } & 0.093018 & 0.065918 & 0.330078 & 0.189453 \\ \text { barren Soil1 } & 0.142090 & 0.176514 & 0.277344 & 0.363525\end{array}$

Table 1. TOA reflectance Values of the sample pixels used for sensitivity analysis

Knowledge based hierarchical approach has been implemented for the detection of the wetland vegetation. The required knowledge generation has been carried out with the help of the display of the false color image (MNDWI - NDPI - NDVI) for the identification. Due to impact of the water turbidity and soil types on the MIR reflectance and the computed NDVI values, combination of MNDWI, NDPI, NDWI and NDT were used in hierarchical, multi parameter threshold of these indices for the identification of wetland vegetation. The visual inspection of the results on the wetland vegetation showed that the algorithm is able to extract vegetation near the water bodies and the aquatic vegetation effectively. Figure 6 shows the LISS III sub image of a water body having aquatic vegetation and the extracted results as insert (green colour) and the ground truth photos of the area located near Korba.

\section{CONCLUSIONS}

An automatic method based on the spectral features has been developed for the extraction of the wetland feature categories such as surface water spread, wetland area, turbidity and wetland vegetation has been developed using the Knowledge based approach and implemented in hierarchical multiple logic equations with multi-parameter decision tree technique. The algorithm was used for extraction of wetland features for Chhattisgarh state of India using pre and post monsoon data sets of IRS Resourcesat LISS III sensor. The evaluation and validation of the results was carried out by a combination ground truth validation and inspection of the results with hybrid Visual-Digital techniques and has been found to be satisfactory. The FCC image layers along with FCC image of computed image layers of the spectral indices were used for during the evaluation of the results. The accuracy estimation was carried out using stratified random sampling technique in the case of LISS-III image Path-Row 103-56 and the true pixel classes were identified by using the ground truth classes, where ever available and using the hybrid visual interpretation technique. The accuracy estimation has been carried out for each of the feature classes separately. This is due the fact that these classes are of overlapping in nature, for example the pixel containing aquatic vegetation (Wetland vegetation) has to be classified as surface water and wetland class pixel also. In the accuracy estimation about 500 sample pixels were used containing approximately half the number of sample belongs to the given wetland feature class. The user accuracy of greater than $90 \%$ has been obtained for all the classes, except that of the high turbidity level classes. This may be due to the subjective nature of the of the estimation of the turbidity level used in the hybrid visual technique. The result in this case is $80 \%$ with 8 pixels correctly classified out of the total of 10 pixels in this category. The small number of samples of this group is due to the smaller extent of the highly turbid water pixels present in the image. Figure 7 shows the FCC image of the scene and the classified image for post monsoon water spread along with the insert showing the expanded image of a small portion of the image. It can be observed that the algorithm is able to detect small water bodies of $3 \times 3$ pixels in size and in some cases smaller that that size also. It was also able to identify water bodies that has aquatic vegetations with in the water body also. These results show the usefulness of the algorithm for regular monitoring of the wetland features. The algorithm was used for the extraction of wetlands for the India state of Chattisgarh. Figure 8 . shows the statistics of the wetland features obtained for different districts Chhattisgarh state. 


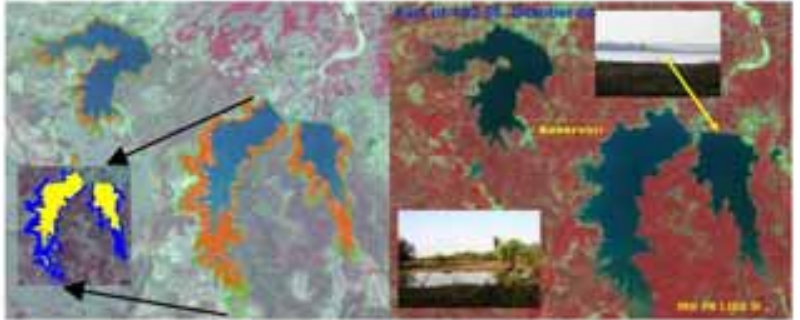

Fig 2 Resourcesat LISS III Data of October 06 and may 07 shows variation in water spread in Tandula reservoir. The classified image of May shows the seasonal change in water spread Post (Blue color) and Pre monsoon (yellow color) as insert image

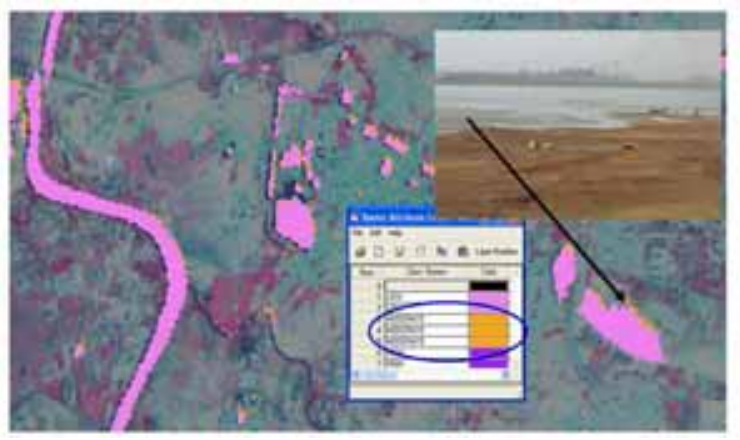

Figure 3. Turbidity Level of Maroda Tank, Durg
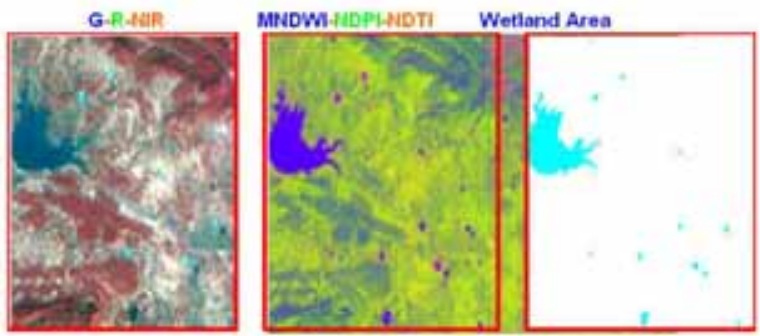

Figure 4. Results of automated Wetland area extraction

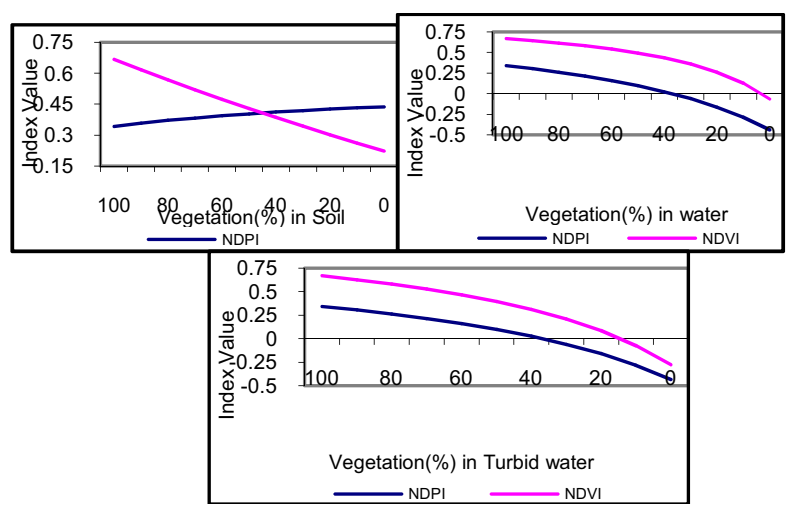

Figure 5 Sensitivity analysis - Plot of the spectral indices as a function of vegetation fraction contribution to the total reflectance-

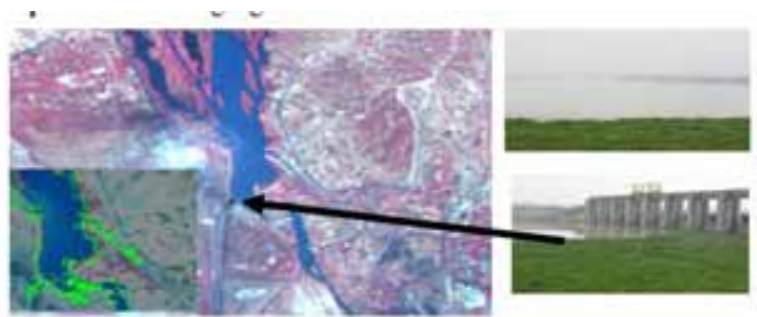

Figure 6. Aquatic Vegetation seen near Korba

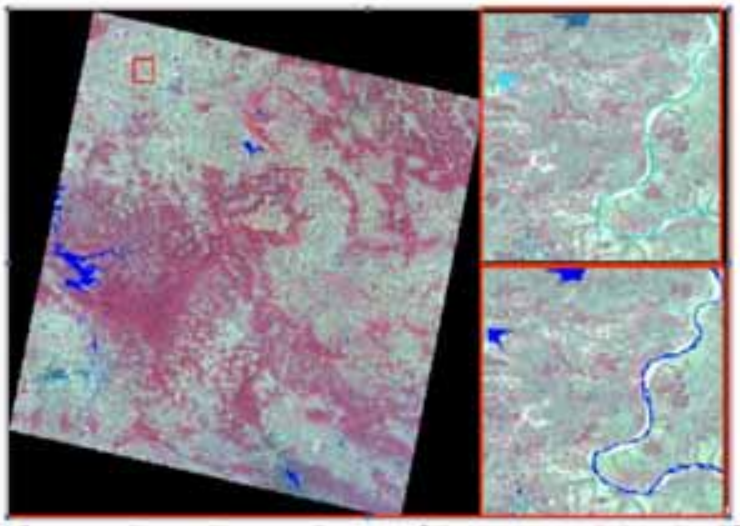

Figure 7 shows the FCC image of the scene and the classified image for post monsoon water spread along with the insert showing the expanded image of a small portion of the image

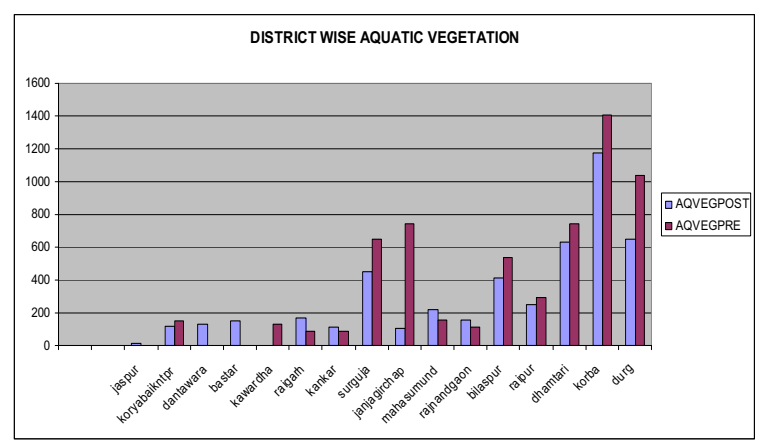

Figure 8. shows the statistics of the wetland features obtained for different districts Chhattisgarh state.

\section{REFERENCES}

Baraldi, A., Puzzolo, V., Blonda, P., Bruzzone, L., and Tarantino, C., 2006, " Automatic spectral rule-based preliminary mapping of calibrated Landsat TM and ETM + Images ",IEEE Trans. Geoscience and Remote Sensing , vol. 44, pp 2563-2586.

C. J. Tuckera and P. J. Sellersa, 1986 "Satellite remote sensing of primary production", International Journal of Remote Sensing, Vol. 7, No. I I, 1395-1416.

Cowardin,L.M., Carter, V., Golet, F.C. and Laroe, E.T., 1979, Classification of wetlands and deepwater habitats of the United States. US Department of the Interior, Fish and Wildlife Service, Washington, DC (Jamestown, ND: Northern Prairie Wildlife

Research

Center 
Online(http://www.npwrc.usgs.gov/resource /wetlands/classwet/index.htm(ver.04 December1998).

Els R. De Roeck, Niko E.C. Verhoest, Mtemi H. Miya, Hans Lievens , Okke Batelaan, Abraham Thomas and Luc Brendonck, 2008" Remote Sensing and Wetland Ecology: a South African Case Study", 8, 3542-3556

Frazier, P. S., and Page, K. J., 2000, “ Water body detection and delineation with Landsat TM data “,Photogrammetric Engineering \& Remote Sensing 66 pp 1461-1467.

J.P. Lacaux, Y.M. Tourre, C. Vignolles, J.A. Ndione, M. Lafaye, 1986, "Classification of ponds from high-spatial resolution remote sensing: Application to Rift Valley Fever epidemics in Senegal", Remote Sensing of Environment 106 , 66-74.

Manavalan, P., Sathyanath, P., Rajegowda, G.L., 1993, "Digital Image Analysis Techniques to Estimate Water spread for Capacity Evaluations of Reservoirs", Photogrammetric Engineering \& Remote Sensing, vol. 59, 1389-1395.

Martha S. Gilmore, Emily H. Wilson, Nels Barrett, Daniel L. Civco, Sandy Prisloe ,James D. Hurd and Cary Chadwick, 2008" Integrating multi-temporal spectral and structural information to map wetland vegetation in a lower Connecticut River tidal marsh", Remote Sensing of Environment 112 , $4048-4060$

McFeeters, S.K., 1996, “ The use of normalized difference water index (NDWI) in the delineation of open water features", International Journal of Remote sensing, vol. 17, pp. 14251432 .

Md.A. Islam, P. S. Thenkabail, R. W. Kulawardhana, R. Alankara; S.Gunasinghe, C. Edussriya; A.Gunawardana, 2008" Semi-automated methods for mapping wetlands using Landsat ETM+ and SRTM data", International Journal of Remote Sensing, Vol. 29, No. 24, 20 pp. 7077-7106

Monirul Islam and Kimiteru Sado, 2006. "Analyses of ASTER and Spectroradiometer data with in situ measurements for turbidity and transparency study of lake Abashri", International Journal of Geoinformatics. Vol. 2. 31-45.
RAMSAR 2004, The Ramsar Convention Manual: A Guide to the Convention on Wetlands (Ramsar, Iran, 1971), $3^{\text {rd }}$ ed., RAMSAR Convention Secretariat, Gland, Switzerland (http://www.ramsar.org/lib/ lib_manual2004e.htm).

Ryu, J. H., Won, J. S., and Min, K. D., 2002, “ Water-line extraction from Landsat TM data in a tidal flat. A case study in Gomso Bay, Korea ",Remote Sensing of Environment. 83 pp 442-456.

Subramaniam,S., Suresh Babu, A.V., and Roy, P.S., 2011 “ Automated Water Spread Mapping Using Resourcesat-1 AWiFS Data for Waterbodies Information System", IEEE Journal of Selected Topics in Applied Earth Observation and remote Sensing", Vol.4. No.1 pp 205-215.

Suresh Babu, A.V., Shanker, M., Venkateshwar Rao., Bhanumurthy, V., 2003, "Generation of water Spread contours for tungabhadra reservoir during low water levels of the year 2002 using satellite remote sensing technique",. GIS India 2003, 8-1 $0^{\text {th }}$ January 2003, Jaipur, India.

Townshend, Justice, 1986 "Analysis of the dynamics of African vegetation using the normalized difference vegetation index", International Journal of Remote Sensing, 1986, Vol. 7, No. II, 1435-1445.

$\mathrm{Xu}$, Hanqiu., 2006, “ Modification of normalize difference water index (NDWI) to enhance open water features in remotely sensed imagery", International Journal of Remote Sensing, vol.27, pp.3025-3033.

Zhang Shu-qing ${ }^{1}$, Zhang Shi-kui ${ }^{1}$ and Zhang Jun-yan, 2000" A study on wetland classification model of remote sensing in the Sangjiang plain", Journal of Chinese Geographic Science, Vol. 10, No.1, pp 68-73

\section{ACKNOWLEDGEMENT}

The authors are thankful to Director, NRSC for encouraging the research on this topic and providing full support during the execution of the development activity. The authors are also thankful to Deputy Director, RS\& GIS_AA. The authors are also thankful to the Arjith Roy and Padma Rani for their contribution in the evaluation of the results. 